\title{
Perspectivas futuras de tratamiento en la insuficiencia cardíaca: del trasplante de células a la regeneración cardíaca
}

\author{
Felipe Prósper, Jesús Herreros y Joaquín Barba \\ Servicio de Hematología y Área de Terapia Celular. Departamento de Cardiología y Cirugía Cardiovascular. \\ Clínica Universitaria. Universidad de Navarra. Pamplona. España.
}

En los últimos años hemos asistido a un interés creciente por el tratamiento de la insuficiencia cardíaca mediante el trasplante de células madre. Mientras que los estudios con células madre de músculo (mioblastos) se iniciaron hace más de 10 años, la posibilidad de que las células madre de la médula ósea tengan un enorme potencial de diferenciación y proliferación ha estimulado la investigación con otros tipos de células madre. Estos estudios experimentales han demostrado, en no pocas ocasiones, resultados contradictorios, lo que ha llevado a posturas enfrentadas en cuanto a la ética de iniciar estudios clínicos. Creemos que es adecuado tratar de ofrecer una visión crítica respecto a la utilización de las células madre en la insuficiencia cardíaca. Quizá la pregunta más difícil de contestar en este momento es si la realización de ensayos clínicos está justificada o no a la luz de los conocimientos actuales, o si por el contrario debemos adquirir un conocimiento mucho más preciso de la posible eficacia de este tipo de tratamiento y de los mecanismos que justifican esta eficacia, antes de siquiera iniciar los estudios en humanos. En nuestra opinión, hay suficientes evidencias que justifican el desarrollo de ensayos clínicos a pesar de que, sin duda, existen muchos interrogantes que debemos resolver mediante estudios experimentales en animales.

Palabras clave: Células madre. Mioblastos. Regeneración cardíaca. Versatilidad.

\section{Future Perspectives in the Treatment of Heart Failure: From Cell Transplantation to Cardiac Regeneration}

The last few years have witnessed growing interest in regenerative therapy for the failing heart by cell transplantation. Although initial studies with skeletal myoblasts are more than 10 years old, the potential of bone marrow-derived cells has led to a flurry of experimental studies generating generally positive but occasionally contradictory results. This has given rise on not a few occasions to conflicting viewpoints regarding the ethics of initiating clinical trials. We feel it is appropriate to offer a critical view of the use of stem cells for heart failure. Perhaps the thorniest question to answer at this time is whether clinical trials are justified or not in the light of current knowledge, or whether we should acquire deeper knowledge of the possible efficacy and safety of this type of treatment, and of the mechanisms that account for its efficacy, before we so much as initiate studies in humans. We feel there is now sufficient evidence to justify the performance of clinical trials despite the undoubtedly numerous questions that remain to be answered with experimental studies in animals.

Key words: Stem cells. Myoblasts. Cardiac regeneration. Plasticity.

Full English text available at: www.revespcardiol.org

\section{INTRODUCCIÓN}

La terapia celular con células madre como estrategia para regenerar tejidos dañados o destruidos aparece como una de las áreas más prometedoras en el tra-

\section{Sección patrocinada por el Laboratorio Dr. Esteve}

Trabajo financiado en parte por ayudas del Ministerio de Ciencia y Tecnología (SAF 2002-04574-C02), Fondos Europeos FEDER (INTERREG IIIA) y la Universidad de Navarra (PIUNA).

Correspondencia: Dr. F. Prósper.

Servicio de Hematología y Área de Terapia Celular.

Av. Pío xii, 36. 31008 Pamplona. España.

Correo electrónico: fprosper@unav.es

Recibido el

Aceptado para su publicación el tamiento de un número muy importante de pacientes afectos de enfermedades y con escasas o nulas expectativas de curación mediante los tratamientos existentes en la actualidad. La insuficiencia cardíaca se presenta como una de las enfermedades más atractivas para el tratamiento mediante la terapia celular, debido a su alta incidencia y prevalencia junto a la ausencia de un tratamiento curativo, con excepción del trasplante cardíaco ${ }^{1}$. A lo largo de los últimos 10 años se ha podido demostrar que el injerto de células de diversos orígenes en las regiones dañadas del corazón puede resultar funcionalmente beneficioso. Obviamente, cuanto mayores son las expectativas que despierta un determinado tratamiento, debemos ser más prudentes en su aplicación y valoración de los resultados, y tra- 
tar por todos los medios de ajustarnos a criterios científicos para evitar resultados adversos que comprometan el futuro del nuevo tratamiento. Tenemos un ejemplo reciente con la utilización de la terapia génica ${ }^{2,3}$.

En cualquier caso, en nuestra opinión, los datos experimentales junto con los resultados de los primeros estudios en pacientes, justifican el desarrollo de ensayos clínicos bien diseñados y rigurosamente controlados en el campo de la terapia celular de la insuficiencia cardíaca. Reconocemos que en este punto hay diversidad de opiniones, desde la perspectiva más optimista hasta visiones significativamente más restrictivas $^{4}$. No cabe duda de que existen numerosas incógnitas y limitaciones que deben investigarse y resolverse antes de que la terapia celular pueda pasar a formar parte del arsenal terapéutico en la insuficiencia cardíaca, pero pensamos que no estaría justificado exigir la respuesta a todas nuestras preguntas antes de iniciar los ensayos clínicos.

A lo largo de las siguientes páginas trataremos de identificar algunos de los obstáculos y las cuestiones más relevantes relacionadas con la aplicación de la terapia celular en cardiología, como el tipo de células, el mecanismo de acción, la vía de administración, los posibles efectos secundarios o las indicaciones. A pesar de los numerosos estudios existentes, la mayor parte de estas cuestiones no tiene hoy día una respuesta clara. Uno de los beneficios del desarrollo de la medicina regenerativa es el estímulo que representa para el desarrollo de nuevas técnicas diagnósticas de evaluación de la función, la viabilidad, la perfusión, etc. No vamos a discutir ninguno de estas facetas por falta de espacio, así como tampoco aspectos más concretos como la vía óptima de administración de las células, o cuáles son las indicaciones de la terapia celular, ya que nos parece un poco prematuro establecer indicaciones de un tratamiento en investigación. Existen revisiones recientes excelentes que abordan algunos de estos aspectos ${ }^{5}$.

\section{REGENERACIÓN CARDÍACA CON CÉLULAS MADRE: ¿CUÁL ES EL TIPO IDEAL DE CÉLULAS?}

Aunque desde un punto de vista teórico, las posibilidades incluyen la utilización de cardiomiocitos, células madre embrionarias, cardíacas, mioblastos esqueléticos o células madre derivadas de la médula ósea, nos centraremos principalmente en las células actualmente disponibles para su utilización clínica, esto es, células derivadas de la médula ósea y mioblastos esqueléticos.

\section{Mioblastos esqueléticos}

Existen numerosas razones por las cuales las células satélite o mioblastos fueron el primer tipo de células madre en utilizarse con el objetivo de regenerar el miocardio: su capacidad proliferativa in vitro, el hecho de tratarse de células con un programa de desarrollo limitado al tejido muscular y, por tanto, con mínimas probabilidades de desarrollar tumores, la posibilidad de obtener células autólogas y su gran resistencia a la isquemia. Numerosos estudios experimentales utilizan mioblastos esqueléticos en modelos de infarto agudo y crónico en roedores, pero también en animales de mayor tamaño, como cerdos u ovejas ${ }^{6}$. Todos estos estudios han permitido llegar a una serie de conclusiones que constituyen la justificación de los ensayos clínicos realizados hasta el momento y que tratamos de resumir a continuación: los mioblastos esqueléticos implantados en animales con un infarto de miocardio son capaces de injertar, tanto en la zona del infarto como alrededor del infarto, y diferenciarse en miotubos multinucleados. Aunque en algún estudio fue posible detectar las células implantadas hasta 12 meses después del trasplante ${ }^{7}$, en la mayoría de los estudios el seguimiento se limita a períodos entre las 4 y las 12 semanas, por tanto, la supervivencia a largo plazo de las células implantadas es un aspecto que no tiene respuesta de forma clara. Por otra parte, el porcentaje de células capaces de injertar en el miocardio, incluso pocas semanas tras el implante celular, es extremadamente bajo: oscila entre el 1 y el $6 \%$ de las células implantadas 8 .

La mayoría de los estudios experimentales han demostrado, asimismo, que el trasplante de mioblastos contribuye significativamente a mejorar la función cardíaca, mejorando principalmente la función sistólica (fracción de eyección), pero en algunos casos también la función diastólica. En general, los estudios publicados sugieren que la mejora de la función es proporcional al número de mioblastos injertados ${ }^{9,10}$ y esta mejora se mantiene en el tiempo. Aunque algunos de los estudios iniciales sugerían que los mioblastos esqueléticos eran capaces de adquirir propiedades similares a las del músculo cardíaco e incluso transdiferenciarse y establecer conexiones electromecánicas ${ }^{11}$, en la actualidad las evidencias indican que no se produce una transdiferenciación de los mioblastos y que, además, las fibras musculares esqueléticas no son capaces de acoplarse mecánicamente con el resto de los cardiomiocitos ni establecer uniones densas ${ }^{12}$. Sin embargo, también parece claro que las fibras musculares esqueléticas son capaces de adquirir ciertas características de células musculares cardíacas y expresar fibras musculares de contracción lenta y rápida, lo que favorece su resistencia a la fatiga muscular (fig. 1).

En este punto merece la pena comentar un estudio recientemente publicado por el grupo de Murry ${ }^{13}$, que ha podido demostrar, en un modelo de ratón, que los mioblastos esqueléticos son capaces de fusionarse con células musculares cardíacas in vivo. Si estos resultados pueden ser reproducidos por otros grupos, justificarían la utilización de los mioblastos esqueléticos 
Fig. 1. Oultivo de mioblastos humanos. Panel superior: identificación mediante citometría de flujo de mioblastos esqueléticos me diante la expresión del antígeno CD56, ausencia de expresión del antígeno CD45. Asimismo, los mioblastos esqueléticos son positivos para desmina. Panel infe rior: mediante inmunofluorescencia, los mioblastos expresan factores transcripcionales asocia dos a diferenciación muscular (MyoD) y desmina

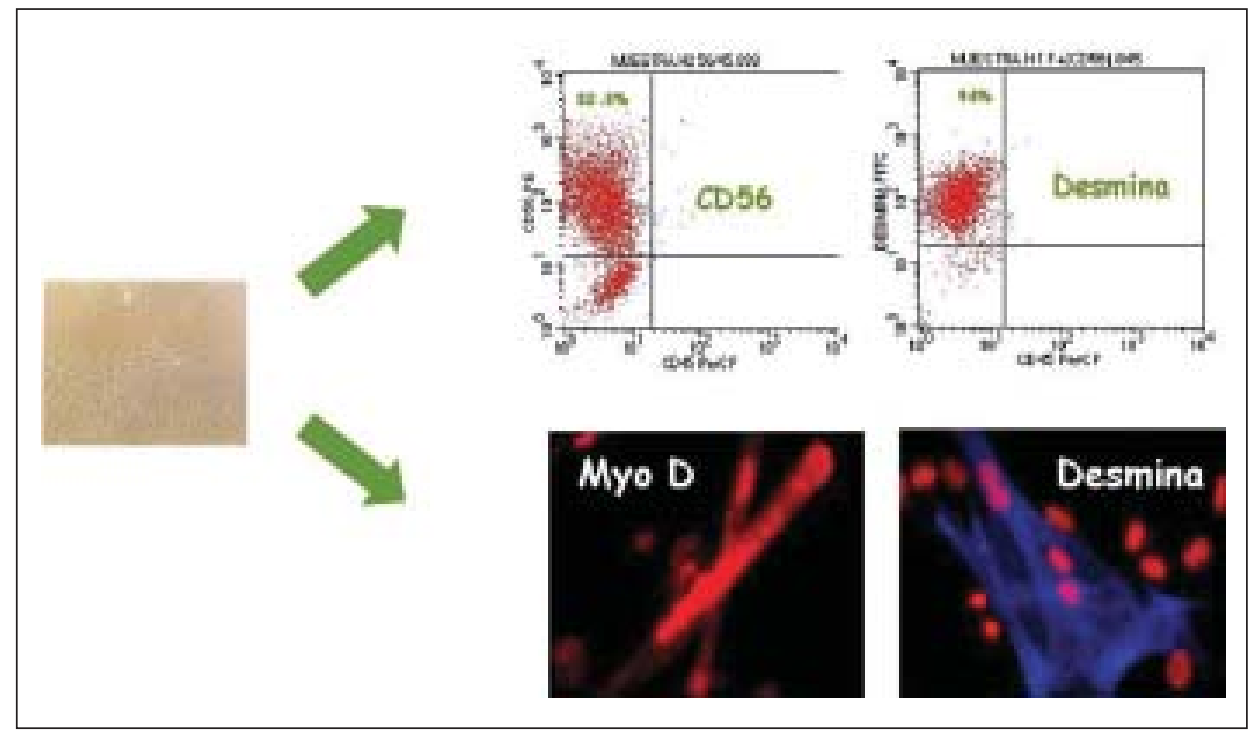

como estrategia de regeneración cardíaca demostrando que al menos uno de los posibles mecanismos de acción sería la fusión entre las células implantadas y los cardiomiocitos residentes en el corazón.

Hasta el momento se han publicado 5 estudios clínicos en fase I con mioblastos esqueléticos autólogos en pacientes con afección cardíaca. Los resultados obtenidos con el primer paciente tratado mediante la administración intracardíaca directa de mioblastos fueron publicados por el grupo de Menasche ${ }^{14}$, que posteriormente describió los resultados obtenidos en un ensayo en fase I con un total de 10 enfermos ${ }^{15}$. En este ensayo se incluyó a pacientes con una historia de infarto de miocardio e indicación de cirugía de revascularización coronaria. En el momento de la cirugía se realizó la inyección directa intramiocárdica de mioblastos esqueléticos, previamente obtenidos del propio paciente y cultivados in vitro durante 14-16 días. Los resultados de este estudio muestran que el tratamiento mediante la revascularización junto al trasplante de mioblastos se asoció a una mejoría significativa de la función miocárdica (mejoría del engrosamiento sistólico, y aumento de la fracción de eyección ventricular) junto con signos evidentes, mediante tomografía por emisión de positrones (PET) (fig. 2), de un aumento de viabilidad miocárdica. Desde el punto de vista de los efectos secundarios, el hallazgo más significativo fue la presencia de una alta incidencia de arritmias ventriculares que en 4 pacientes requirieron la implantación de un desfibrilador ventricular. Bien en forma de resumen (estudios en fase I del grupo de Dib con dosis escaladas de mioblastos y del grupo de Siminiak ${ }^{16}$ ) o artículo $^{8,17,18}$, se han publicado los resultados de 6 estudios de regeneración cardíaca con mioblastos esqueléticos. Estos ensayos se han desarrollado en 3 situaciones clínicas distintas: administración intramiocárdica en asociación a cirugía de revascularización aortocoro- naria ${ }^{15-17}$, por vía percutánea mediante administración endocavitaria $^{18}$ o de forma adyuvante a la implantación de un sistema de asistencia ventricular ${ }^{18}$.

¿Qué podemos deducir de los resultados obtenidos en estos estudios? En realidad confirman algunos de los hallazgos descritos en modelos experimentales. En primer lugar estos trabajos demuestran la factibilidad del procedimiento. Al menos en 2 de los estudios, se demuestra anatomopatológicamente que los mioblastos esqueléticos son capaces de injertar en el corazón $^{8,19}$. Por otra parte, es una constante de todos los trabajos que se produce una mejora funcional con un incremento de la fracción de eyección ventricular. Sin embargo, debido a que en la mayor parte de los estudios el tratamiento con células se asocia a la cirugía de revascularización, en estos momentos es imposible determinar si el trasplante de mioblastos contribuye de forma directa a mejorar la función. Merece la pena mencionar que trabajos recientes indican que la cirugía de revascularización contribuye en el mejor de los casos de forma muy limitada a mejorar la función ventricular y, por tanto, apoyarían que el trasplante de mioblastos es eficaz aun desconociendo el mecanismo por el cual induce la mejoría ${ }^{20}$. En cualquier caso, sólo la realización de estudios aleatorizados con y sin administración de mioblastos junto a la cirugía de revascularización permitirán determinar de forma definitiva la eficacia de esta estrategia terapéutica. Al menos 3 estudios aleatorizados están en marcha en Francia, España y EE.UU. La administración percutánea también permitiría determinar la eficacia del tratamiento con mioblastos, como sugiere el único estudio publicado hasta el momento ${ }^{18}$.

Uno de los aspectos más controvertidos de la utilización de mioblastos, de hecho no anticipado por los estudios experimentales, ha sido la aparición de arritmias cardíacas $^{8,15}$. Aunque existen diversas hipótesis, 


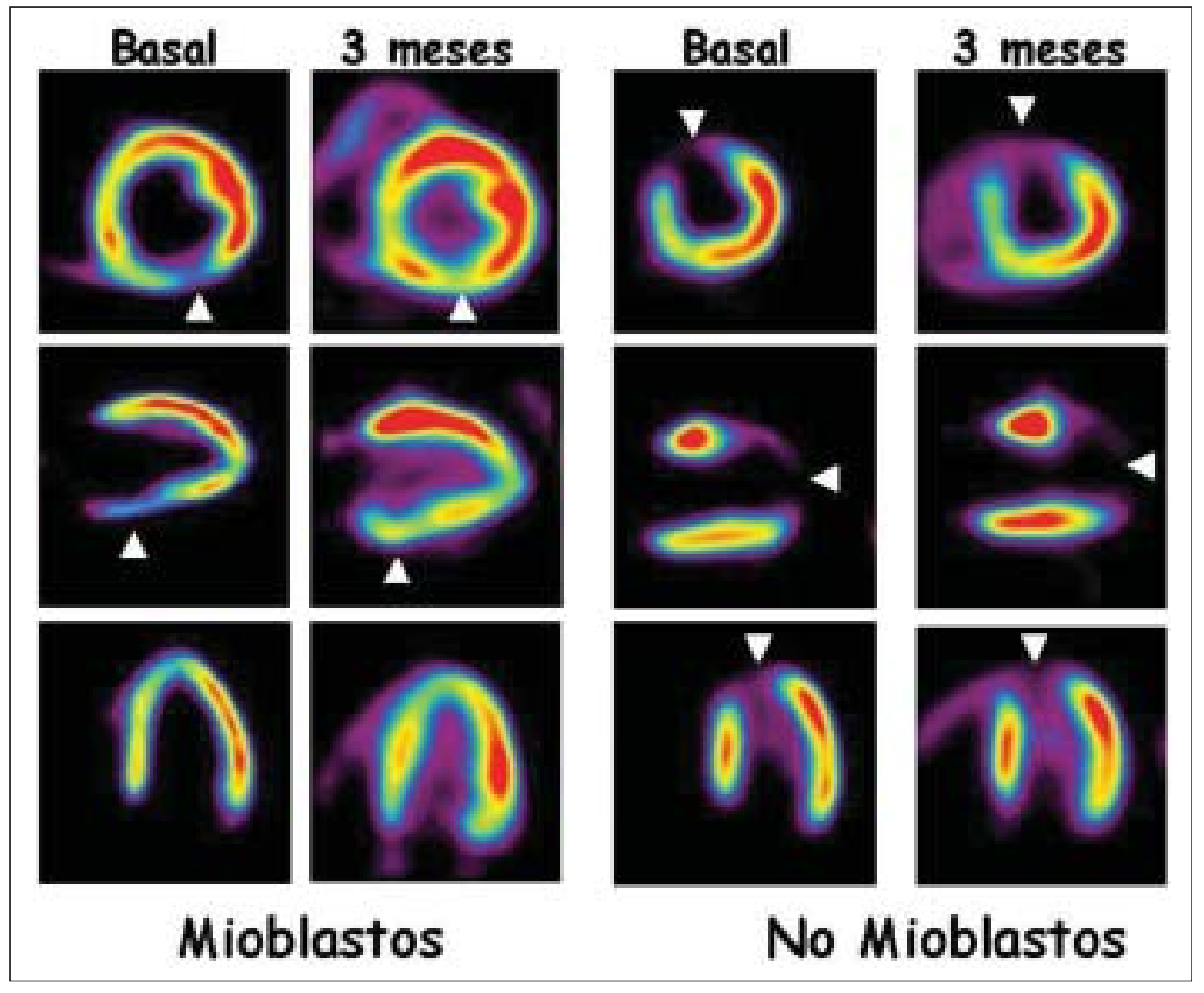

Fig. 2. Imagen mediante tomografía por emisión de positrones (PET) con flúor-18-desoxiglucosa (PDG). Panel izquierdo corresponde a la imagen mediante PET en un paciente con un infarto de miocardio antiguo. Las cabezas de flecha señalan un déficit de captación de FDG consistente con una imagen de necrosis. A los 3 meses tras la realización de una cirugía de revascularización junto con el implante de mioblastos autólogos, se aprecia una mejora muy significativa en la captación de FDG consistente con un aumento de la viabilidad. 日 panel derecho corresponde a un paciente sometido a cirugía de revascularización pero sin trasplante de células, donde se aprecia que no mejora la viabilidad del tejido. se desconoce el mecanismo por el cual se producirían estas arritmias y de hecho la presencia de arritmias no ha sido un fenómeno constante en todos los estudios ${ }^{17}$. Aunque es un aspecto relevante, en estos momentos no se puede afirmar que el trasplante de mioblastos induzca arritmias cardíacas. Los resultados de los nuevos ensayos clínicos y experimentales deberán determinar si los mioblastos son arritmogénicos y cuál es su posible mecanismo.

Una pregunta fundamental es ¿cuál es el mecanismo por el cual los mioblastos pueden contribuir a mejorar la función cardíaca? En este sentido, existen algunas hipótesis y ninguna certeza. Es posible que los mioblastos esqueléticos faciliten la elasticidad del músculo cardíaco, limitando la extensión del infarto e impidiendo el remodelado ventricular. Sería un efecto exclusivamente mecánico dependiente de la formación de una estructura que sustente el músculo pero con un papel puramente pasivo. Un segundo mecanismo podría depender de la liberación de distintas sustancias y factores de crecimiento por parte de los mioblastos. Estas sustancias permitirían la reorganización de la matriz extracelular (secreción de metaloproteasas) ${ }^{21}$, la inducción de angiogénesis (factor de crecimiento endotelial vascular) e incluso la movilización y el anidamiento de las células madre derivadas de otros teji$\operatorname{dos}^{22}$. Aunque existen numerosas evidencias en contra de la integración de los mioblastos con los cardiomiocitos, los estudios recientes que demuestran la fusión entre mioblastos y cardiomiocitos apoyarían la posibilidad de que los mioblastos pudieran actuar por que favorecerían directamente la función sistólica, al integrarse en el músculo cardíaco. En nuestra opinión, sin entrar a discutir los argumentos por limitaciones de espacio, esta hipótesis nos parece poco probable. Es posible que sean varios los mecanismos que contribuyan a su eficacia, y de hecho en situaciones agudas o crónicas los mecanismos puedan ser diferentes. En el infarto agudo, actuar sobre el modelado ventricular puede ser más eficaz, mientras que en el crónico un mecanismo mecánico pasivo puede ofrecer ventajas. Independientemente de cuál sea el mecanismo, es indudable que los estudios en animales junto con las evidencias clínicas preliminares justifican continuar los ensayos clínicos que nos permitan determinar la eficacia terapéutica de este tratamiento.

\section{Células derivadas de la médula ósea}

En este caso el panorama se complica, ya que existen diferentes poblaciones de células madre en la médula ósea con capacidad, al menos in vitro, de diferenciarse en células musculares cardíacas o endoteliales y contribuir a la función contráctil, y a la angiogénesis y vasculogénesis. La médula ósea es un complejo microambiente formado por distintos tipos de células maduras, células comprometidas y células madre o troncales. A diferencia de lo que ha ocurrido en el caso de 
los mioblastos esqueléticos, donde tras varios años de estudios experimentales se han iniciado los estudios en pacientes, en el caso de la médula ósea se ha implementado la aplicación clínica con una menor evidencia preclínica de eficacia, lo que no significa que no exista una base racional para su utilización sino exclusivamente una menor documentación de eficacia en modelos animales.

Podemos dividir los estudios de regeneración cardíaca con células de médula ósea en aquellos que han empleado poblaciones sin seleccionar, los que han utilizado células madre purificadas (endoteliales o hematopoyéticas) y los que usan células mesenquimales.

La mayor parte de los estudios clínicos realizados hasta el momento con células madre de médula ósea han utilizado células sin seleccionar, es decir un pool celular que incluye células madre y células diferenciadas. A nuestro juicio, los motivos que justifican esta aproximación son fáciles de entender: es un procedimiento simple (realizar una selección celular mediante un gradiente de densidad es asequible a cualquier laboratorio), es barato y no está sujeto a los mismos trámites regulatorios que se exige en el caso de la manipulación celular in vitro. Desde el punto de vista teórico, al utilizar toda la población celular de la médula ósea evitamos perder células potencialmente útiles, bien por su capacidad de diferenciarse en cardiomiocitos o células endoteliales, o gracias a su capacidad de liberar sustancias que favorezcan la regeneración celular. Por el contrario, introducimos tipos celulares capaces de inducir efectos adversos al liberar sustancias inflamatorias. En general, los estudios experimentales realizados con células mononucleadas de médula ósea ofrecen resultados discordantes. Mientras que algunos trabajos indican una mejoría de la vascularización y función cardíaca ${ }^{23,24}$, otros estudios no demuestran ningún beneficio ${ }^{25,26}$. La heterogeneidad de las células implantadas dificulta la comparación de estos estudios. Clínicamente, se han inyectado células mononucleadas de médula ósea o sangre periférica mediante inyección intracoronaria en pacientes con infarto agudo de miocardio sometidos a angioplastia ${ }^{27-29}$, o en pacientes con isquemia crónica utilizando sistemas de guiado electromecánico ${ }^{30-32}$. El objetivo de estos estudios ha sido demostrar la factibilidad del tratamiento y su posible eficacia en cuanto a la mejoría de la función cardíaca, la perfusión y la viabilidad tisular. Los resultados del tratamiento con las células se han comparado, en algunos de los estudios, con grupos control tratados de forma similar pero a los que no se administró células, aunque sin que se trate de ensayos clínicos aleatorizados ${ }^{27,30}$. En su conjunto, estos ensayos sugieren que el tratamiento se acompaña de una mejora en la función cardíaca junto a un aumento de la perfusión del miocardio. La hipótesis más aceptada es que las células mononucleadas aumentan la vascularización y la angiogénesis del tejido, aunque ciertamen- te este punto no ha sido demostrado en modelos experimentales ni en humanos. Recientemente, se ha realizado un estudio comparativo en pacientes con infarto agudo tratados mediante la implantación de un stent posteriormente aleatorizados en 3 grupos: pacientes que han recibido células mononucleadas de sangre periférica movilizadas con factor estimulador de colonias granulocíticas (G-CSF), pacientes que han recibido GCSF o un grupo control. La alta incidencia de reestenosis en los pacientes tratados con G-CSF ha obligado a detener el ensayo y a cuestionar los posibles efectos secundarios asociados a este tipo de tratamiento y añadido cierto grado de escepticismo a la terapia celular ${ }^{28}$.

Una segunda opción consiste en la utilización de poblaciones de células madre con un potencial demostrado al menos en modelos in vitro. El fenotipo de las células madre hematopoyéticas de la médula ósea en el ratón está perfectamente definido y las distintas poblaciones de células madre, caracterizadas en detalle. Sin embargo, en humanos, por razones obvias, no se han realizado estudios de reconstitución, por lo que las poblaciones de células madre de médula ósea no han sido tan bien definidas como en el ratón. Sin embargo, existen marcadores asociados a células madre hematopoyéticas y endoteliales, como son la expresión de los antígenos CD34 y de AC133.

La utilización de células madre hematopoyéticas se sustenta en la existencia de estudios en modelos animales, principalmente rata y ratón, en los que se demuestra la capacidad de distintas poblaciones de células madre de diferenciarse a células endoteliales e incluso a cardiomiocitos, contribuyendo a mejorar la función cardíaca. Pensamos que debido a que estudios recientes cuestionan de forma directa y explícita estos trabajos iniciales, merece la pena dedicar unas líneas a discutirlos, antes de describir la situación desde el punto de vista clínico.

Los primeros estudios de regeneración cardíaca con células madre hematopoyéticas utilizaron células side population en un modelo de isquemia en el ratón ${ }^{33} \mathrm{o}$ células CD34 administradas de por vía intravenosa en un modelo de infarto ${ }^{34}$. En ambos estudios se demostraba que las células madre hematopoyéticas eran capaces de contribuir a la regeneración del miocardio, gracias a su capacidad de favorecer la angiogénesis y la vasculogénesis $\mathrm{y}$, posiblemente, a la capacidad de estas células de diferenciarse a cardiomiocitos. Sin embargo, el estudio que mostró los resultados más espectaculares fue el publicado por el grupo de Orlic y Anversa en el que, utilizando un modelo de infarto agudo en ratón y la administración de células madre hematopoyéticas Lin-c-kit+ (población purificada de células madre hematopoyéticas), demostraron que estas células eran capaces de diferenciarse, in vivo, a cardiomiocitos y células endoteliales, contribuyendo a mejorar la contractilidad miocárdica y la supervivencia de los animales ${ }^{35}$. La controversia ha surgido a raíz 
de 2 trabajos recientemente publicados en la revista Nature, en los cuales se cuestiona no sólo el hecho de que las células madre hematopoyéticas se diferencien a cardiomiocitos, sino que se pone en duda directamente los estudios de Orlic e indirectamente cualquier evidencia de transdiferenciación ${ }^{36,37}$. Si bien es cierto que el trabajo de Orlic estimuló el desarrollo clínico de la terapia celular con células madre en pacientes con infarto, sería injustificado pretender que toda la base científica que sustenta los ensayos clínicos en pacientes con infarto de miocardio está en este estudio. No viene al caso una discusión pormenorizada de estos 3 estudios discordantes, pero al menos queremos recordar algunos aspectos en concreto de los dos últimos estudios publicados: se trata de 2 estudios con resultados negativos y, por tanto, como todo estudio con hallazgos negativos, supeditados a que, simplemente, el modelo utilizado no sea el adecuado; por otra parte, lo único que podemos concluir de estos ensayos es que determinada población de células madre hematopoyéticas de ratón en un modelo de infarto agudo no se diferencia a cardiomiocito (excepto mediante fusión), pero no podemos hablar de ineficacia terapéutica debido a que en uno de los 2 estudios ni siquiera se evalúa ${ }^{36}$, y en el otro los resultados sugieren una leve mejora de la función en los animales tratados con las células $^{37}$. Por último, estos trabajos sólo estudian la capacidad de una población de células madre muy concretas, células madre hematopoyéticas, y teniendo en cuenta que en la médula ósea existen otros tipos de células madre, no se puede concluir que las células de médula ósea no son capaces de regenerar el miocardio. Ambos trabajos, en la discusión y conclusión del artículo, cuestionan que se realicen ensayos clínicos, conclusión desde nuestro punto de vista injustificada y que tal vez se podría modificar de la siguiente manera: deben hacerse ensayos clínicos, cuidadosamente diseñados y controlados, y con preguntas concretas y relevantes.

Un nuevo estudio, publicado hace escasamente unas semanas, añade una nueva perspectiva: nuevamente utilizando células madre hematopoyéticas y un modelo de infarto en el ratón, se demuestra que es posible obtener cardiomiocitos a partir de células madre hematopoyéticas, pero que el mecanismo es mediante fusión celular $^{38}$, hallazgo que concuerda con un estudio previo $^{39}$.

Desde el punto de vista clínico, se han utilizado células madre endoteliales (también conocidas como células endoteliales progenitoras [EPC]) administradas por vía intracoronaria en pacientes con infarto agudo de miocardio, con la hipótesis de que estas células contribuirían a mejorar la angiogénesis y a recuperar tejido hibernado ${ }^{40}$. En este estudio, se comparó la eficacia de las EPC derivadas de la médula ósea frente a las obtenidas de sangre periférica y frente a un grupo control. Los resultados funcionales, así como los estu- dios de perfusión mediante PET, sugieren la eficacia de las células madre endoteliales. Entre las células madre de médula ósea, la población de células AC133 positivas se considera particularmente enriquecida en progenitores hemagioblásticos, capaces de diferenciarse en endotelio y en células hematopoyéticas. El potencial de estas células, junto a la posibilidad técnica de purificarlas a partir de médula ósea humana o sangre periférica, ha favorecido su utilización clínica, descrita por primera vez en un grupo de pacientes con un infarto antiguo y sometidos a cirugía de revascularización coronaria ${ }^{41}$. A la vista de los resultados iniciales, en los que con dosis de tan sólo $10 \times 10^{6}$ células AC133 se pudo demostrar una mejora de la función y la perfusión miocárdicas, este mismo grupo ha iniciado un estudio aleatorizado en el que los pacientes recibieron tratamiento con células AC133 y cirugía de revascularización, o exclusivamente cirugía. Los resultados preliminares con los primeros 20 pacientes indican una superioridad del grupo tratado con células AC133 respecto a la recuperación funcional (comunicación personal).

Aunque la utilización de las células madre mesenquimales como estrategia de regeneración cardíaca tan sólo se ha utilizado en modelos animales, este tipo celular presenta un atractivo especial, principalmente por su capacidad in vitro de diferenciarse a células musculares cardíacas, y además por la posibilidad de obtener un número importante de células de manera sencilla, eficaz y relativamente económica. Las células mesenquimales se pueden obtener a partir de varios tejidos, principalmente médula ósea y tejido graso (también conocido como fracción de estroma vascular). Las células mesenquimales, tanto de la grasa como de la médula ósea, han demostrado su capacidad para diferenciarse in vitro en células de músculo cardíaco $\mathrm{y}$, a la vez, en células endoteliales, haciéndolas especialmente atractivas no sólo por que pueden regenerar el miocardio, sino por que contribuyen a la neoangiogénesis y vasculogénesis $^{42-44}$. En modelos experimentales de infarto de miocardio en rata y en cerdo, se han empleado células mesenquimales de médula ósea que demostraron su capacidad de mejorar la función cardíaca ${ }^{45}$ y diferenciarse en células musculares cardíacas ${ }^{46}$. Incluso fue posible utilizar células mesenquimales modificadas genéticamente con un factor de supervivencia y conseguir mejorar enormemente la supervivencia celular tras el implante en ratones infartados ${ }^{47}$. No existen, sin embargo, estudios clínicos publicados con células mesenquimales en pacientes con infarto de miocardio.

\section{CONCLUSIONES}

El punto fundamental de la controversia existente es si las células madre adultas (hematopoyéticas o de otro tipo) son capaces de transdiferenciarse o si las observaciones que sugieren la existencia de este fenómeno 
pueden explicarse mediante otros mecanismos, como la fusión celular o incluso simplemente se tratan de interpretaciones incorrectas de resultados experimentales. Discutir este tema en detalle excede el objetivo de esta revisión, pero para aquellos lectores interesados sugerimos algunas revisiones recientes al respecto ${ }^{48,49}$. Sin embargo, nos parece importante tratar de transmitir una serie de ideas que esperamos puedan ayudar al lector a llegar a sus propias conclusiones en un área de la medicina con un alto componente emocional, y así poder interpretar un poco más críticamente muchos de los estudios publicados:

1. Las células madre de médula ósea no son exclusivamente células madre hematopoyéticas, por tanto las generalizaciones conllevan a confusiones. Por ejemplo, es posible que las células madre hematopoyéticas no se diferencien a músculo cardíaco, pero las células AC133 o CD34 de la médula ósea sin duda no son exclusivamente células madre hematopoyéticas, sino que también incluyen células madre endoteliales e incluso mesenquimales. Por tanto, es posible que su capacidad diferenciadora sea mucho mayor que la de las células hematopoyéticas

2. No es absolutamente fundamental que exista una transdiferenciación de las células madre y una integración funcional en el tejido para que sean eficaces; es indudable que sería lo ideal, pero que no ocurra no excluye que su utilización pueda contribuir al beneficio terapéutico.

3. Se producen fenómenos de fusión celular, tanto in vitro como in vivo, entre células madre y células residentes en el tejido. Sin embargo, la fusión celular puede ser un fenómeno de reparación celular, como es el caso del músculo esquelético, donde un daño del tejido se recupera mediante la proliferación de células satélite y su posterior fusión al trasformarse en miofibras. En el caso concreto del corazón, merece la pena recordar que el músculo cardíaco está formado por células conectadas y, por tanto, «fusionadas».

4. Al menos in vitro, ha sido claramente demostrado que es posible reprogramar células e inducir fenómenos de transdiferenciación. Si este fenómeno existe in vivo y hasta qué punto está por demostrarse.

5. Si bien conocer los mecanismos por los cuales un determinado tratamiento es eficaz antes de aplicarlo es el objetivo de la medicina, invitamos al lector a preguntarse de cuántos tratamientos actualmente aceptados como eficaces, y utilizados diariamente, conoce todos los mecanismos por los que funciona, y todos los posibles efectos secundarios, sin que por ello deje de utilizarlos. Sería ideal seguir los criterios que plantea Chien ${ }^{4}$ antes de iniciar la aplicación clínica de las células madre, pero no sería realista y ni siquiera ético impedir el beneficio de muchos miles de pacientes para satisfacer el conocimiento científico (existen multitud de ejemplos en la historia de la medicina). Esto no excluye nuestra responsabilidad de realizar una in- vestigación objetiva y estricta que nos lleve a clarificar los posibles mecanismos por los que este tipo de tratamiento puede funcionar ${ }^{50}$.

\section{BIBLIOGRAFÍA}

1. Rodríguez-Artalejo F, Banegas Banegas JR, Guallar-Castillon P. Epidemiología de la insuficiencia cardíaca. Rev Esp Cardiol 2004;57:163-70.

2. Check E. Cancer fears cast doubts on future of gene therapy. Nature 2003;421:678.

3. Check E. Harmful potential of viral vectors fuels doubts over gene therapy. Nature 2003;423:573-4.

4. Chien KR. Stem cells: lost in translation. Nature 2004;428:607-8.

5. Orlic D, Hill JM, Arai AE. Stem cells for myocardial regeneration. Circ Res 2002;91:1092-102.

6. Menasche P. Skeletal muscle satellite cell transplantation. Cardiovasc Res 2003;58:351-7.

7. Ghostine S, Carrion C, Souza LC, Richard P, Bruneval P, Vilquin JT, et al. Long-term efficacy of myoblast transplantation on regional structure and function after myocardial infarction. Circulation 2002;106:I131-6.

8. Pagani FD, DerSimonian H, Zawadzka A, Wetzel K, Edge ASB, Jacoby DB, et al. Autologous skeletal myoblasts transplanted to ischemia-damaged myocardium in humans. J Am Coll Cardiol 2003;41:879-88.

9. Taylor DA, Atkins BZ, Hungspreugs P, Jones TR, Reedy MC, Hutcheson KA, et al. Regenerating functional myocardium: improved performance after skeletal myoblast transplantation. Nat Med 1998;4:929-33.

10. Pouzet B, Vilquin JT, Hagege AA, Scorsin M, Messas E, Fiszman M, et al. Factors affecting functional outcome after autologous skeletal myoblast transplantation [discussion 850-1]. Ann Thorac Surg 2001;71:844-50;

11. Reinecke H, MacDonald GH, Hauschka SD, Murry CE. Electromechanical coupling between skeletal and cardiac muscle. Implications for infarct repair. J Cell Biol 2000;149:731-40.

12. Leobon B, Garcin I, Menasche P, Vilquin JT, Audinat E, Charpak S. Myoblasts transplanted into rat infarcted myocardium are functionally isolated from their host. Proc Natl Acad Sci USA 2003;100:7808-11.

13. Reinecke H, Minami E, Poppa V, Murry CE. Evidence for fusion between cardiac and skeletal muscle cells. Circ Res 2004;94:e5660.

14. Menasche P, Hagege AA, Scorsin M, Pouzet B, Desnos M, Duboc $\mathrm{D}$, et al. Myoblast transplantation for heart failure. Lancet 2001;357:279-80.

15. Menasche P, Hagege AA, Vilquin JT, Desnos M, Abergel E, Pouzet B, et al. Autologous skeletal myoblast transplantation for severe postinfarction left ventricular dysfunction. J Am Coll Cardiol 2003;41:1078-83.

16. Siminiak T, Fiszer D, Jerzykowska O, Grygielska B, Kalmucki P, Kurpisz M. Percutaneous autologous myoblast transplantation in the treatment of post-infarction myocardial contractility impairment-report on two cases. Kardiol Pol 2003;59:492-501.

17. Herreros J, Prosper F, Pérez A, Gavira JJ, García-Velloso MJ, Barba J, et al. Autologous intramyocardial injection of cultured skeletal muscle-derived stem cells in patients with non-acute myocardial infarction. Eur Heart J 2003;24:2012-20.

18. Smits PC, Van Geuns RJ, Poldermans D, Bountioukos M, Onderwater $\mathrm{EE}$, Lee $\mathrm{CH}$, et al. Catheter-based intramyocardial injection of autologous skeletal myoblasts as a primary treatment of ischemic heart failure: clinical experience with six-month follow-up. J Am Coll Cardiol 2003;42:2063-9.

19. Hagege AA, Carrion C, Menasche P, Vilquin JT, Duboc D, Marolleau JP, et al. Viability and differentiation of autologous skele- 
tal myoblast grafts in ischaemic cardiomyopathy. Lancet 2003;361:491-2.

20. Allman KC, Shaw LJ, Hachamovitch R, Udelson JE. Myocardial viability testing and impact of revascularization on prognosis in patients with coronary artery disease and left ventricular dysfunction: a meta-analysis. J Am Coll Cardiol 2002;39:1151-8.

21. Zhang M, Methot D, Poppa V, Fujio Y, Walsh K, Murry CE. Cardiomyocyte grafting for cardiac repair: graft cell death and anti-death strategies. J Mol Cell Cardiol 2001;33:907-21.

22. Askari AT, Unzek S, Popovic ZB, Goldman CK, Forudi F, Kiedrowski M, et al. Effect of stromal-cell-derived factor 1 on stemcell homing and tissue regeneration in ischaemic cardiomyopathy. Lancet 2003;362:697-703.

23. Tomita S, Li RK, Weisel RD, Mickle DA, Kim EJ, Sakai T, et al. Autologous transplantation of bone marrow cells improves damaged heart function. Circulation 1999;100:II247-56.

24. Kamihata H, Matsubara H, Nishiue T, Fujiyama S, Tsutsumi Y, Ozono R, et al. Implantation of bone marrow mononuclear cells into ischemic myocardium enhances collateral perfusion and regional function via side supply of angioblasts, angiogenic ligands, and cytokines. Circulation 2001;104:1046-52.

25. Agbulut O, Menot ML, Li Z, Marotte F, Paulin D, Hagege AA, et al. Temporal patterns of bone marrow cell differentiation following transplantation in doxorubicin-induced cardiomyopathy. Cardiovasc Res 2003;58:451-9.

26. Bel A, Messas E, Agbulut O, Richard P, Samuel JL, Bruneval P, et al. Transplantation of autologous fresh bone marrow into infarcted myocardium: a word of caution. Circulation 2003;108(Suppl 1):II247-52.

27. Strauer BE, Brehm M, Zeus T, Kostering M, Hernandez A, Sorg $\mathrm{RV}$, et al. Repair of infarcted myocardium by autologous intracoronary mononuclear bone marrow cell transplantation in humans. Circulation 2002;106:1913-8.

28. Kang HJ, Kim HS, Zhang SY, Park KW, Cho HJ, Koo BK, et al. Effects of intracoronary infusion of peripheral blood stem-cells mobilised with granulocyte-colony stimulating factor on left ventricular systolic function and restenosis after coronary stenting in myocardial infarction: the MAGIC cell randomised clinical trial. Lancet 2004;363:751-6.

29. Avilés FF, San Román JA, García Frade J, Valdés M, Sánchez A, De la Fuente L, et al. Regeneración miocárdica mediante la implantación intracoronaria de células madre en el infarto agudo de miocardio. Rev Esp Cardiol 2004;57:201-8.

30. Perin EC, Dohmann HF, Borojevic R, Silva SA, Sousa AL, Mesquita CT, et al. Transendocardial, autologous bone marrow cell transplantation for severe, chronic ischemic heart failure. Circulation 2003;107:2294-302.

31. Tse HF, Kwong YL, Chan JK, Lo G, Ho CL, Lau CP. Angiogenesis in ischaemic myocardium by intramyocardial autologous bone marrow mononuclear cell implantation. Lancet 2003;361:47-9.

32. Fuchs S, Satler LF, Kornowski R, Okubagzi P, Weisz G, Baffour $\mathrm{R}$, et al. Catheter-based autologous bone marrow myocardial injection in no-option patients with advanced coronary artery disease: a feasibility study. J Am Coll Cardiol 2003;41:1721-4.

33. Jackson KA, Majka SM, Wang H, Pocius J, Hartley CJ, Majesky MW, et al. Regeneration of ischemic cardiac muscle and vascular endothelium by adult stem cells. J Clin Invest 2001;107:1395-402.
34. Kocher AA, Schuster MD, Szabolcs MJ, Takuma S, Burkhoff D, Wang J, et al. Neovascularization of ischemic myocardium by human bone-marrow-derived angioblasts prevents cardiomyocyte apoptosis, reduces remodeling and improves cardiac function. Nat Med 2001;7:430-6.

35. Orlic D, Kajstura J, Chimenti S, Jakoniuk I, Anderson SM, Li B, et al. Bone marrow cells regenerate infarcted myocardium. Nature 2001;410:701-5.

36. Balsam LB, Wagers AJ, Christensen JL, Kofidis T, Weissman IL, Robbins RC. Haematopoietic stem cells adopt mature haematopoietic fates in ischaemic myocardium. Nature 2004;428:668-73.

37. Murry CE, Soonpaa MH, Reinecke H, Nakajima H, Nakajima HO, Rubart M, et al. Haematopoietic stem cells do not transdifferentiate into cardiac myocytes in myocardial infarcts. Nature 2004;428:664-8.

38. Nygren JM, Jovinge S, Breitbach M, Sawen P, Roll W, Hescheler $\mathrm{J}$, et al. Bone marrow-derived hematopoietic cells generate cardiomyocytes at a low frequency through cell fusion, but not transdifferentiation. Nat Med 2004;10:494-501.

39. Alvarez-Dolado M, Pardal R, Garcia-Verdugo JM, Fike JR, Lee HO, Pfeffer K, et al. Fusion of bone-marrow-derived cells with Purkinje neurons, cardiomyocytes and hepatocytes. Nature 2003;425:968-73.

40. Assmus B, Schachinger V, Teupe C, Britten M, Lehmann R, Dobert N, et al. Transplantation of Progenitor Cells And Regeneration Enhancement in Acute Myocardial Infarction (TOPCAREAMI). Circulation 2002;106:3009-17.

41. Stamm C, Westphal B, Kleine HD, Petzsch M, Kittner C, Klinge $\mathrm{H}$, et al. Autologous bone-marrow stem-cell transplantation for myocardial regeneration. Lancet 2003;361:45-6.

42. Planat-Benard V, Silvestre JS, Cousin B, Andre M, Nibbelink M, Tamarat R, et al. Plasticity of human adipose lineage cells toward endothelial cells: physiological and therapeutic perspectives. Circulation 2004;109:656-63.

43. Planat-Benard V, Menard C, Andre M, Puceat M, Perez A, Garcia-Verdugo JM, et al. Spontaneous cardiomyocyte differentiation from adipose tissue stroma cells. Circ Res 2004;94:223-9.

44. Makino S, Fukuda K, Miyoshi S, Konishi F, Kodama H, Pan J, et al. Cardiomyocytes can be generated from marrow stromal cells in vitro. J Clin Invest 1999;103:697-705.

45. Shake JG, Gruber PJ, Baumgartner WA, Senechal G, Meyers J, Redmond JM, et al. Mesenchymal stem cell implantation in a swine myocardial infarct model: engraftment and functional effects [discussion 1926]. Ann Thorac Surg 2002;73:1919-25.

46. Toma C, Pittenger MF, Cahill KS, Byrne BJ, Kessler PD. Human mesenchymal stem cells differentiate to a cardiomyocyte phenotype in the adult murine heart. Circulation 2002;105:93-8.

47. Mangi AA, Noiseux N, Kong D, He H, Rezvani M, Ingwall JS, et al. Mesenchymal stem cells modified with Akt prevent remodeling and restore performance of infarcted hearts. Nat Med 2003;9:1195-201

48. Raff M. Adult stem cell plasticity: fact or artifact? Annu Rev Cell Dev Biol 2003;19:1-22.

49. Wagers AJ, Weissman IL. Plasticity of adult stem cells. Cell 2004;116:639-48.

50. Couzin J, Vogel G. Cell therapy. Renovating the heart. Science 2004;304:192-4. 